\title{
Paediatric care in the United States
}

\author{
Laurence Finberg
}

This is the third paper in a series showing the problems facing the medical services for children in different countries.
Children's Medical Center of Brooklyn, State University of New York, Health Science Center Science Cente
at Brooklyn

Correspondence to: Professor Laurence Finberg, Children's Medical Center of Brooklyn, Kings County Hospital Center, University Hospital of Brooklyn, 450 Clarkson Avenue, Box 49, Brooklyn NY 11203-2098, USA
In writing this invited essay, I shall look at some of the problems facing the delivery of medical care to children of the US and not point to the glories of our successes of which there are many. On this side of the Atlantic we have pursued a system in which the general paediatric specialist (three years training in an accredited paediatric programme and successful passage of American Board of Pediatrics certifying examination) is both a primary care physician for children and a consultant to other specialists. To become a subspecialist additional training is required, now three years. Such persons are usually hospital based and care for patients within their specialised field, frequently giving primary care as well. This last varies from region to region and even from institution to institution. Some see this system as working well, others see it as a problem. We need more time to resolve the matter which I believe will happen as we address the more pressing problems of improving our medical care delivery system's economic basis. My experience as an educator and programme director leads me to believe that at least two years of training in paediatrics by paediatricians is needed for competency in the primary care of children and that at least three years of total (four would be better) postgraduate training is necessary for the average resident.

A few other thoughts should be reviewed before focusing on particular issues. Some of us believe health care is a 'right' akin to liberty and the pursuit of happiness. Others, for good reason, disagree and certainly our present legal system does not decree such a right. As a long time physician to children of the inner city I have believed all of my career that basic health care for children should be a mandated 'right' superseding even the wishes of parents. How much health care needs to be decided. I do not believe it will be hard to define 'basic' in this context.

So much has been said about the problems of delivery of health care in the US that any writing tends to be repetitive. Let us first list some of the facts generally agreed upon.

(1) Our costs are very high-nearly $12 \%$ of the gross national product and rising, far more than anyone else.

(2) Children have been getting proportionately less government monetary resource than the elderly, a situation which had been worsening until this year.

(3) Some of the outcome measures, for example, infant mortality, show the US lagging well behind other industrial nations, though this too has finally shown a spurt of improvement.
(4) One of the reasons for improvement, the availability for abortions for unwanted children, is under attack and we have seen retrogression in programmes for the poor where such programmes have been especially useful in lowering infant mortality. The antiabortion groups of course will say that mortality has been simply displaced in time, without that group having a parallel concern for the misery and hardships produced without these programmes.

(5) We profess a great unwillingness to ration medical care while at the same time actually rationing it by income rather than some other method.

(6) The private insurance system of payment and our tort laws have spurred a system where 'defensive medicine' and high malpractice premiums have increased the cost of care.

(7) The magnificent technologies we (and others) invent and produce have greatly advanced therapeutic medicine but not preventive medicine to our detriment. Some fortunate recipients of high tech care have benefited but other instances have only added to cost. In particular we can postpone dying long after useful life has ceased and have in so doing enormously raised costs.

(8) We abuse our treasured freedom by unwise personal conduct with respect to alcohol, drugs, tobacco, and promiscuity that add to our burden of illness without an economic penalty for these actions, another major cost item.

(9) Largely because the economic rewards for specialists, particularly those who perform procedures, are appreciably greater than for those who give 'primary care', our medical school graduates quite naturally compete for the more remunerative specialties which then have a high proportion of 'the best and brightest'.

I will now focus on a few of the problems of US health care as they relate to children: infant mortality, preventive services, and the disproportionate rewards for procedural services.

First a look at infant mortality. The prelude to birth, of course, is pregnancy. There is a clear positive association between appropriate prenatal care and good outcome in pregnancy. Many observers, missing the lack of a cause and effect relationship between these two, assume that simply more available access to prenatal care will solve the problem. I believe it will do little, because many (probably) of the women who do not get prenatal care do not seek it because they live in circumstances where health care for themselves or their fetus is simply not a high, or even moderate, priority. Some do not seek care because of ignorance. I therefore believe that the most important components of a programme to increase successful prenatal care 
requires measures to motivate and to inform the young women.

Of the two, motivation is the more important and the more difficult. One suggestion is to provide jobs for the economic underclass community so that there is hope for a better life. This of course requires political will and some sacrifice, probably through taxation, for the affluent. Simultaneously we should improve the education of the economically deprived so that they can at some point in the near future qualify for jobs requiring skills not now possessed in their community. Investment in these two areas will, I believe, ultimately pay off handsomely to the whole society. This suggestion goes outside of medicine to larger issues of the society. Medicine can ameliorate but not alone solve society's ills.

Ignorance about health matters can be reduced by introducing an understanding of the role of preventive measures and parenting at an early point in the school curriculum and reinforcing the information every year from about the age of 10 onwards. This last can be done easily and the paediatric community should be given a leadership role in devising the curriculum and perhaps even directly teaching some of it.

Preventive services must be administered to all children if we are to maximise our knowledge and improve children's health. I include here encouraging breast feeding, supervision of nutrition, plotting the points on the growth curve at appropriate and regular intervals, and administering immunisations to all except a few who may be medically vulnerable. Here we have failed to educate our physicians sufficiently in that minor illness is not a contraindication for immunisation. Much of the immunisation programme can be carried out without visits to a physician and we should return to that type of programme where suitable. Education about sexual behaviour and about harmful substances should also be a routine part of the school curriculum as a national necessity without regard to the precepts of groups who would hide information and proscribe protective measures against disease and unwanted pregnancy.

Finally we find that our medical students, following their own reasonable self interest, do not, in sufficient numbers, choose careers that will best serve society's interest. In a free country we have only a few options. Like many before me I believe some form of nationalised system of medical care is needed, a system that will provide a comfortable economic niche for all physicians by redistributing the rewards toward 'cognitive' services and away from procedures. A redesign of fee structure will be needed rewarding (to a degree) length of training, difficulty of procedure, and the outcome performance of the physician, with a clear limit to annual reimbursement from the plan. These last remarks of course get beyond the field of paediatrics but are highly germane and, of course, very controversial.

I have not dealt with the problems of access to high technology and to the high cost of dying because these topics are now under debate and do not lend themselves to a solution that I can visualise. I do think that that new procedures should have a designated period when they are 'experimental' and not made widely available. Then each should be introduced and made available more generally after there is reason to believe it will prevent disease or sustain productive life. The individual decisions about the prolongation of dying I believe properly belong in the domain of physicians - not the courts with obligatory consultation with other physicians of experience.

The foregoing essay has provided a mixture of facts and highly personal opinion bearing on the solution to some of our problems. Some of these issues have also been reviewed in a single issue of the American Fournal of Diseases of Children, May 1991; 145:489-580. Other views and suggestions are recorded there for the interested reader. 